\title{
Polymerization of Diketene
}

\section{$\operatorname{AUTHOR}(\mathrm{S})$ :}

Furukawa, Junji; Saegusa, Takeo; Mise, Noritoshi; Kawasaki, Akihiro

\section{CITATION:}

Furukawa, Junji ...[et al]. Polymerization of Diketene. Bulletin of the Institute for Chemical Research, Kyoto University 1961, 39(3): 264-264

ISSUE DATE:

1961-07-31

URL:

http://hdl.handle.net/2433/75805

RIGHT: 


\section{ABSTRACTS}

\section{Crystalline Polyaldehydes}

Junji Furukawa, Takeo Saegusa, Hiroyasu Fumi, Akihiro Kawasaki, Hirosuke Imar, and Yoshikazu Fujn

Makromol. Chem., 37, 149 (1960)

We found that aldehydes such as acetaldehyde propionaldehyde and trichloroacetaldehyde were polymerized by organometallic compound or by metal alkoxide to give crystalline resinous polymer of high molecular weight.

Crystalline polyacetaldehydehyde was much less soluble in organic solvents than the amorphous one. The infra-red spectrum of crystalline polyacetaldehyde was shwn to be sharper than that of amorphous one and to have specific absorption bands, although it indicated also the structure of methyl polyoxymethylene.

Active species of this polymerization was supposed to be the metal alkoxide.

\section{Polymerization of Diketene}

Junji Furukawa, Takeo Saegusa, Noritoshi Mise, and Akihiro KAWASAKI

Makromol. Chem., 39, 243 (1960)

It was found that mercuric chloride polymerized diketene to give the polymer of polyester structure (I). The molecular weight of this polymer was 1630 . The structure of the polymer was assumed by the infra-red spectrum. The alkalialcoholysis of the polymer with ethanol gave ethylacetoacetate (II), and this finding supports the structure (I).

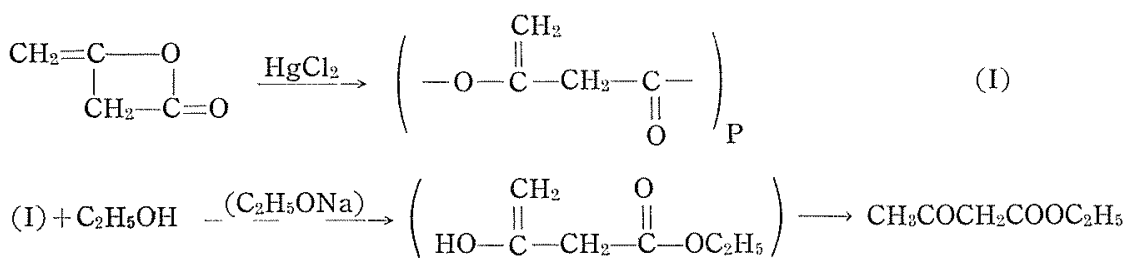

Polymerization of Olefins by the Binary Mixture of Organometallic Compond and Silica-Alumina-Titania

Junji Furumawa, Takeo Saegusa, Teiji Tsuruta, Shiro Anzal, Tsuneaki NarumiYa and Akihiro KawASAKI

Makromol. Chem., 41, 17 (1960)

Silica-alumina-titania was prepared by the hydrolysis of a mixture of ethyl orthosilicate, alumilinum isopropoxide and ethyl orthotitanate followed by calcination. The catalyst consisting of silica-alumina-titania (wt. ratio 45:5:50) and 